\title{
Synthesis, Spectral and Thermal Characterization of Bis(pyridine-3- carboxy-2-thiolato-S)mercury(II). Crystal Structure of Dibromobis(3- metoxycarbonylpyridine-2-thiolato-S)mercury(II) ${ }^{\dagger}$
}

\author{
Željka Soldin, ${ }^{\mathrm{a}, *}$ Dražen Vikić-Topić, ${ }^{\mathrm{b}}$ Gordana Pavlović, ${ }^{\mathrm{c}}$ Marijana Vinković, ${ }^{\mathrm{b}}$ \\ Dubravka Matković-Čalogović, ${ }^{a}$ and Zora Popović ${ }^{\mathrm{a}}$
}

${ }^{a}$ Division of General and Inorganic Chemistry, Department of Chemistry, Faculty of Science, University of Zagreb, Horvatovac 102a, HR-10000 Zagreb, Croatia

${ }^{\mathrm{b}}$ Ruđer Bošković Institute, NMR Centre, P. O. Box 180, HR-10002 Zagreb, Croatia ${ }^{\mathrm{c}}$ Faculty of Textile Technology, Department of Applied Chemistry, University of Zagreb, Prilaz baruna Filipovića 28a, HR-10000 Zagreb, Croatia

\begin{abstract}
H}_{2} \mathrm{mna}=2-\mathrm{HS}\left(\mathrm{C}_{5} \mathrm{H}_{3} \mathrm{~N}\right) \mathrm{COOH}\right)$ gave a thiolato compound of the formula $\mathrm{Hg}(\mathrm{Hmna})_{2}$ by a reaction with various mercury(II) salts, $\mathrm{HgX}_{2}\left(\mathrm{X}=\mathrm{Cl}^{-}, \mathrm{Br}^{-}, \mathrm{I}^{-}, \mathrm{SCN}^{-}\right)$in an ethanol or methanol solution irrespectively of the molar ratio of the reactants $(1: 1$ or $1: 2)$. The same compound was obtained from the reaction of mercury(II) acetate in an aqueous-ethanol solution. $\mathrm{Hg}(\mathrm{Hmna})_{2}$ was characterized by vibrational spectroscopy and thermal analysis. ${ }^{1} \mathrm{H}$ and ${ }^{13} \mathrm{C}$ NMR measurements provided additional information on the thiol-thione tautomerism in $\mathrm{H}_{2}$ mna and $\mathrm{Hg}(\mathrm{Hmna})_{2}$ and also on the binding mode to mercury in the DMSO- $\mathrm{d}_{6}$ solution. $\mathrm{HgBr}_{2}\left(\mathrm{CH}_{3}-\mathrm{Hmna}\right)_{2}$ was obtained from the reaction of $\mathrm{H}_{2}$ mna with $\mathrm{HgBr}_{2}$ in methanol after filtering off the main product $\mathrm{Hg}(\mathrm{Hmna})_{2} \quad\left(\mathrm{CH}_{3}-\mathrm{Hmna}=2\right.$ $\left.\mathrm{HS}\left(\mathrm{C}_{5} \mathrm{H}_{3} \mathrm{~N}\right) \mathrm{COOCH}_{3}\right)$. The crystal structures of $\mathrm{H}_{2}$ mna and $\mathrm{HgBr}_{2}\left(\mathrm{CH}_{3}-\mathrm{Hmna}\right)_{2}$ were determined by the $\mathrm{X}$-ray structure analysis. 2-mercaptonicotinic acid exists in the crystalline state in the thione tautomeric form. Two bromine atoms and two S-bound $\mathrm{CH}_{3}-\mathrm{Hmna}$ ligands form a tetrahedral coordination sphere around the mercury atom in $\mathrm{HgBr}_{2}\left(\mathrm{CH}_{3}-\mathrm{Hmna}\right)_{2}$.(doi: $\left.10.5562 / \mathrm{cca} 2169\right)$
\end{abstract}

Keywords: 2-mercaptonicotinic acid, mercury complex, thione-thiol tautomerism, X-ray single crystal structure analysis, intra- and intermolecular hydrogen bonds, ${ }^{1} \mathrm{H},{ }^{13} \mathrm{C}$ NMR

\section{INTRODUCTION}

The coordination chemistry of polyfunctional ligands can be interesting from the point of view of their selective binding to different metal ions. They are widespread in biological systems, including amino acids and nucleic acids. It is a well known fact that mercury(II) ions interact with many biological molecules through coordination with a thiole, imidazole, amino or carboxylate group. ${ }^{1}$ The biological chemistry of mercury is dominated by interactions with the cysteine thiolato group which is consistent with Pearson's hard and soft acids and bases (HSAB) principle., ${ }^{2,3}$ Mercury(II) complexes with sulphur-donor ligands can be used to imitate mercury interactions in biological systems. ${ }^{4}$

A common feature of nitrogen-containing heterocyclic thiones is the thione and thiol tautomerism as shown for $\mathrm{H}_{2} \mathrm{mna}$ in Scheme 1. Furthermore the monoanion and dianion forms of $\mathrm{H}_{2} \mathrm{mna}$ can be obtained by deprotonation (Scheme 1).

In the past years complexes of different transition metals with 2-mercaptonicotinic acid have been reported. ${ }^{5-16} \mathrm{H}_{2} \mathrm{mna}$ upon deprotonation exhibits three potential binding sites for metal centers. Deprotonated $\mathrm{H}_{2} \mathrm{mna}$ can act through the pyridine nitrogen atom, carboxylate or thiolate groups as a monodentate, bidentate or bridging ligand, particularly for transition metal ions. Coordination modes found for the monoanion $(\mathrm{a}-\mathrm{e})$ and the dianion (f-h) are shown in Scheme 2.

As a part of our continuous study of mercury(II) complexes with heterocyclic thiones as polyfunctional ligands ${ }^{16-26}$ we investigated the reaction of $\mathrm{H}_{2}$ mna with mercury(II) halides and thiocyanate in ethanol or methanol solutions and in two molar ratios of reactants (1:1 and 2:1). The reaction of mercury(II)

\footnotetext{
$\dagger$ This article belongs to the Special Issue devoted to the $85^{\text {th }}$ anniversary of Croatica Chemica Acta.

* Author to whom correspondence should be addressed. (E-mail: zeljka@chem.pmf.hr)
} 
<smiles>O=C(O)c1cccnc1S</smiles><smiles>OCCO</smiles>

THIOL FORM<smiles>O=C(O)c1cccnc1[S-]</smiles>

MONOANION<smiles>O=C(O)c1ccc[nH]c1=S</smiles>

THIONE FORM<smiles>O=C([O-])c1cccnc1[S-]</smiles>

DIANION

Scheme 1. Thiol, thione tautomers (with enumeration of atoms), monoanion and dianion forms of the 2mercaptonicotinic acid.

acetate and $\mathrm{H}_{2}$ mna in an aqueous-ethanol solution was also investigated. We report here the synthesis and characterization of $\mathrm{Hg}(\mathrm{Hmna})_{2}$ by vibrational spectroscopy and thermal analysis and the crystal structures of uncoordinated $\mathrm{H}_{2}$ mna and of $\mathrm{HgBr}_{2}\left(\mathrm{CH}_{3}\right.$ Hmna $)_{2}$ which were determined by single-crystal Xray structure analysis.

The structure of free $\mathrm{H}_{2}$ mna was reported earlier in a Note describing a silver cluster with 2-mercaptonicotinic acid, however, the description of $\mathrm{H}_{2} \mathrm{mna}$ is very scarce. ${ }^{10}$ In addition, in the manuscript there is no mention of the Flack parameter and the absolute structure determination which we have done here.

\section{EXPERIMENTAL}

Mercury(II) halides, $\mathrm{HgX}_{2}\left(\mathrm{X}=\mathrm{Cl}^{-}, \mathrm{Br}^{-}, \mathrm{I}^{-}\right)$, thiocyanate and acetate were supplied by Kemika (Zagreb, Croatia) while 2-mercaptonicotinic acid was supplied by Aldrich and used without further purification.

\section{Synthesis of Bis(3-carboxypyridine-2-thiolato-S)mer- cury(II), Hg(Hmna)}

\section{i) from mercury(II) acetate}

A solution of 2-mercaptonicotinic acid $(0.97 \mathrm{~g}, 6.26$ mmol) in $200 \mathrm{ml}$ of ethanol was added drop wise to a solution of mercury(II) acetate $(1 \mathrm{~g}, 3.13 \mathrm{mmol})$ in 50 $\mathrm{ml}$ of water (with a few drops of glacial acetic acid). A pale yellow microcrystalline product was filtered off, washed with cold ethanol and dried in air. Yield: $1.49 \mathrm{~g}$ (90\%).

Elemental analysis; found (calculated) for $\mathrm{Hg}\left(\mathrm{C}_{6} \mathrm{H}_{4} \mathrm{NO}_{2} \mathrm{~S}\right)_{2}$ : C 28.32 (28.46); H 1.71 (1.58); N 5.68 (5.50); S 12.54 (12.60); Hg 39.52 (39.41).<smiles>[M]Oc1ncccc1C(=O)O</smiles><smiles></smiles><smiles>[M]OC(=O)c1cccnc1O</smiles>

b<smiles>[M]O[M]1=NN2C=CC=C(C(=O)O)C12</smiles>

d<smiles></smiles><smiles></smiles>

Scheme 2. Coordination modes of 2-mercaptonicotinic acid found in transition metals complexes.

ii) from mercury(II) salts, $\mathrm{HgX}_{2}\left(\mathrm{X}^{\left.-\mathrm{Cl}^{-}, \mathrm{Br}^{-}, \mathrm{I}^{-}, \mathrm{SCN}^{-}\right)}\right.$ An ethanolic or methanolic solution of 2-mercaptonicotinic acid was added drop wise to an ethanolic or methanolic solution of the corresponding mercury(II) salt in an appropriate molar ratio. A pale yellow microcrystalline product was filtered off, washed with cold ethanol and dried in air. Yield: 85-90\%. Results of the elemental analysis confirmed that the reaction product is always $\mathrm{Hg}\left(\mathrm{C}_{6} \mathrm{H}_{4} \mathrm{NO}_{2} \mathrm{~S}\right)_{2}$.

\section{Synthesis of Dibromobis(3-metoxycarbonylpyridine- 2-thiolato-S)mercury(II), $\mathrm{HgBr}_{2}\left(\mathrm{CH}_{3}-\mathrm{Hmna}\right)_{2}$}

A solution of 2-mercaptonicotinic acid (0.26 g, 1.69 $\mathrm{mmol})$ in $150 \mathrm{ml}$ of methanol was added drop wise to a solution of the mercury(II) bromide $(0.30 \mathrm{~g}, 0.83 \mathrm{mmol})$ in $5 \mathrm{~mL}$ methanol. $\mathrm{Hg}(\mathrm{Hmna})_{2}$ was filtered off, washed with cold methanol and dried in air. Yield: $0.39 \mathrm{~g}(90$ \%). From the filtrate a few crystals of $\mathrm{HgBr}_{2}\left(\mathrm{CH}_{3}-\right.$ Hmna $)_{2}$ were obtained in the form of thin needle-shaped stellar conglomerates after two weeks. Unfortunately, the amount was insufficient for elemental and spectroscopic analysis. 


\section{Methods}

IR and Raman spectroscopy

IR-spectra of $\mathrm{KBr}$ pellets were recorded on a PerkinElmer FTIR 1600 spectrometer in the $4500-450 \mathrm{~cm}^{-1}$ region. The Raman spectra in the range $600-100 \mathrm{~cm}^{-1}$ were obtained with a Bruker Equinox 55 spectrometer.

\section{${ }^{1} \mathrm{H}$ and ${ }^{13} \mathrm{C} N \mathrm{NM}$ spectroscopy}

The one- and twodimensional homo- and heteronuclear ${ }^{1} \mathrm{H}$ and ${ }^{13} \mathrm{C}$ NMR spectra were recorded with a Varian Gemini spectrometer, operating at $300.08 \mathrm{MHz}$ for the ${ }^{1} \mathrm{H}$ nucleus and $75.46 \mathrm{MHz}$ for the ${ }^{13} \mathrm{C}$ nucleus. Samples were measured from DMSO- $\mathrm{d}_{6}$ solutions at $20{ }^{\circ} \mathrm{C}(293$ $\mathrm{K}$ ) in $5 \mathrm{~mm}$ NMR tubes. Chemical shifts, in ppm, are referred to TMS as internal standard. FID resolution in ${ }^{1} \mathrm{H}$ NMR and ${ }^{13} \mathrm{C}$ NMR spectra was $0.20 \mathrm{~Hz}$ and 0.60 $\mathrm{Hz}$ per point, respectively. The following measurement techniques were used: standard ${ }^{1} \mathrm{H},{ }^{13} \mathrm{C}$ broadband decoupling, ${ }^{13} \mathrm{C}$ gated proton decoupling, COSY, COSY45, LRCOSY-45, NOESY and HETCOR.

\section{Thermal analysis}

Thermogravimetric analyses were performed using a simultaneous TGA-DTA analyser (Mettler-Toledo TGA/SDTA $851^{\mathrm{e}}$ ). The samples of about $5 \mathrm{mg}$ in mass were placed in aluminium pans $(40 \mu \mathrm{L})$. The TGA and DTA curves were obtained with a heating rate of $10{ }^{\circ} \mathrm{C}$ $\mathrm{min}^{-1}$ and nitrogen flowing at rate of $200 \mathrm{~mL} \mathrm{~min}^{-1}$. The samples were heated from room temperature up to $600{ }^{\circ} \mathrm{C}$. DSC measurements were performed on a Mettler-Toledo DSC $823^{\mathrm{e}}$ module in aluminium pans $(40 \mu \mathrm{L})$, heated in flowing nitrogen $\left(200 \mathrm{~mL} \mathrm{~min}^{-1}\right)$ at a rate of $10{ }^{\circ} \mathrm{C} \mathrm{min}^{-1}$. The samples were heated from room temperature up to $500{ }^{\circ} \mathrm{C}$. The data collection and analysis was performed using the program package STARe Software 9.01. ${ }^{27}$

$X$-ray structural analysis

Single crystals of $\mathrm{H}_{2}$ mna suitable for X-ray diffraction were obtained by recrystallization from dimethylsulfoxide. Data collection was performed on a Philips PW 1100 four circle diffractometer with graphite monochromator and controlled by the program STADI4. ${ }^{28}$ The data were corrected for Lorentz-polarization effects by the program X-RED. ${ }^{29}$

It was difficult to obtain single crystals of $\mathrm{HgBr}_{2}\left(\mathrm{CH}_{3}-\mathrm{Hmna}\right)_{2}$ since they had to be broken from stellar conglomerates of thin needle-shaped crystals. Many crystals had to be tested before finding one of good quality for diffraction. The single-crystal X-ray diffraction data were collected by $\omega$-scans on an Oxford Diffraction Xcalibur 3 CCD diffractometer. Data reduction that included an empirical absorption correction using spherical harmonics was performed using the CrysAlisPro software package. ${ }^{30}$

Solution, refinement and analysis of the structures were done using the programs integrated in the WinGX system. ${ }^{31}$ The structure of $\mathrm{H}_{2}$ mna was solved by direct methods while that of $\mathrm{HgBr}_{2}\left(\mathrm{CH}_{3}-\mathrm{Hmna}\right)_{2}$ was solved by the Patterson method using SHELXS. ${ }^{32}$ The refinement procedure was performed by the full-matrix least-squares method based on $F^{2}$ against all reflections using SHELXL. ${ }^{32}$ The non-hydrogen atoms were refined anisotropically. The Flack parameter confirmed the correct absolute structures. ${ }^{33}$ Graphite-monochromated Mo- $K_{\alpha}$ radiation $(\lambda=0.71073 \AA)$ was used for both data collections at room temperature. Details of data collection and crystal structure refinement are given in Table 1.

The hydrogen atoms belonging to the oxygen $\mathrm{O} 2$ atom of the $\mathrm{COOH}$ group and to the pyridine nitrogen $\mathrm{N}$ atom in $\mathrm{H}_{2}$ mna were found in the difference electrondensity maps at the end of the refinement procedure as a small electron density with appropriate geometry (O1-H1O 0.90(3) $\AA, \mathrm{N}-\mathrm{H} 1 \mathrm{~N} 0.86(2) \AA)$. Location of the hydrogen atom at $\mathrm{O} 1$ was supported further by the geometry of the $\mathrm{COOH}$ group (C6-O2 1.213(2) $\AA$ and C6-O1 1.321(3) A) clearly making difference between single $\mathrm{C}-\mathrm{O}$ and double $\mathrm{C}=\mathrm{O}$ bonds. ${ }^{34}$ The positions of hydrogen atoms belonging to the $\mathrm{Csp}^{2}$ atoms were geometrically optimized applying the riding model $\left(\mathrm{Csp}^{2}-\mathrm{H}\right.$ $\left.0.93 \AA, U_{\text {iso }}(\mathrm{H})=1.2 U_{\text {eq }}(\mathrm{C})\right)$. All hydrogen atoms on the pyridine ring in $\mathrm{HgBr}_{2}\left(\mathrm{CH}_{3}-\mathrm{Hmna}\right)_{2}$ were located in the difference Fourier maps. Because of poor geometry for some of them they were placed in calculated positions and refined using the riding model.

The geometrical calculations and molecular graphics were done with PLATON98 ${ }^{35}$ and Mercury $3.0 .^{36}$

\section{RESULTS AND DISCUSSION}

The reaction of 2-mercaptonicotinic acid with various mercury(II) salts, $\mathrm{HgX}_{2}\left(\mathrm{X}=\mathrm{Cl}^{-}, \mathrm{Br}^{-}, \mathrm{I}^{-}, \mathrm{SCN}{ }^{-}\right)$in an ethanol or methanol solution irrespectively of the molar ratio of the reactants $(1: 1$ or $1: 2)$ resulted in a thiolato compound of the formula $\mathrm{Hg}(\mathrm{Hmna})_{2}$. The same compound was obtained from the reaction of mercury(II) acetate in an aqueous-ethanol solution. Unfortunately all attempts to get single crystals by means of recrystallization and by varying experimental conditions have failed. Quite unexpectedly, $\mathrm{HgBr}_{2}\left(\mathrm{CH}_{3}-\mathrm{Hmna}\right)_{2}$ was obtained from the reaction of $\mathrm{H}_{2}$ mna with $\mathrm{HgBr}_{2}$ in methanol after filtering off the principle product $\mathrm{Hg}(\mathrm{Hmna})_{2}$. In this complex the ester of 2-mercaptonicotinic acid occurred. Such esterification was observed in solutions containing molybdenum complexes. $9,37,38$

\section{IR, Raman and NMR spectra}

Fundamental vibrational modes for $\mathrm{H}_{2} \mathrm{mna}$ and $\mathrm{Hg}(\mathrm{Hmna})_{2}$ were assigned in accordance with the literature data regarding metal complexes with $\mathrm{H}_{2}$ mna. ${ }^{7,8,10,13,39}$ 
Table 1. General and crystal data and summary of intensity data collection and structure refinement for $\mathrm{H}_{2} \mathrm{mna}$ and $\mathrm{HgBr}_{2}\left(\mathrm{CH}_{3}-\mathrm{Hmna}\right)_{2}$

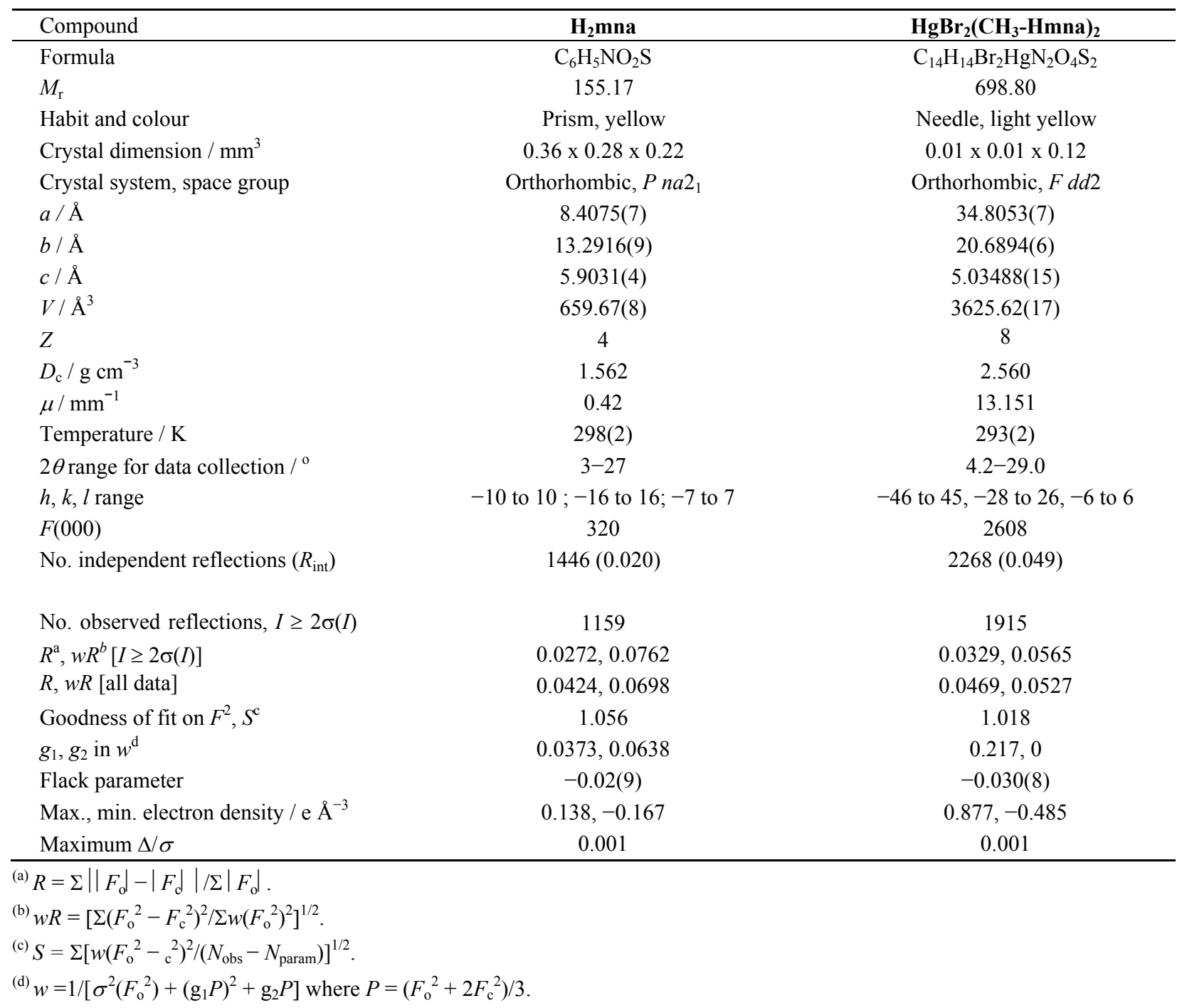

By comparing the IR and Raman spectra of the free ligand molecule and its metal complex we could conclude about the coordination mode of $\mathrm{H}_{2}$ mna. Characteristic IR bands of $\mathrm{H}_{2}$ mna and $\mathrm{Hg}(\mathrm{Hmna})_{2}$ are listed in Table 2 (IR spectra can be requested from the authors as supplementary material). The IR spectra shows vibrational bands which have been assigned mainly to $\mathrm{C}-\mathrm{N}$ modes of the thioamide group (thioamide I and thioamide II) and $\mathrm{C}-\mathrm{S}$ modes of the thioamide group (thioamide III and thioamide IV).

Absence of the $v(\mathrm{~S}-\mathrm{H})$ absorption at $c a .2500$ $\mathrm{cm}^{-1}$ in the IR-spectrum of free $\mathrm{H}_{2} \mathrm{mna}$, and presence of the $v(\mathrm{~N}-\mathrm{H})$ band at $3187 \mathrm{~cm}^{-1}$ and $v(\mathrm{C}=\mathrm{S})$ at 1143 $\mathrm{cm}^{-1}$, suggests that $\mathrm{H}_{2} \mathrm{mna}$ in the solid state exists in the thione rather than the thiol form (Scheme 1). This was also determined by the $\mathrm{X}$-ray structural determination of $\mathrm{H}_{2}$ mna. Position of the band assigned to the $v(\mathrm{C}=\mathrm{O})$
Table 2. Characteristic IR bands $\left(\mathrm{cm}^{-1}\right)$ in $\mathrm{H}_{2} \mathrm{mna}$ and $\mathrm{Hg}(\mathrm{Hmna})_{2}$

\begin{tabular}{lll}
\hline Assignment & $\mathbf{H}_{2} \mathbf{m n a}$ & $\mathbf{H g}(\mathbf{H m n a})_{2}$ \\
\hline$v(\mathrm{~N}-\mathrm{H})$ & $3187 \mathrm{~m}$ & - \\
$\nu(\mathrm{C}=\mathrm{O})$ & $1688 \mathrm{vs}$ & $1686 \mathrm{vs}$ \\
$\delta(\mathrm{N}-\mathrm{H})$ & $1621 \mathrm{~s}$ & - \\
Thioamide I & $1580 \mathrm{vs}$ & $1572 \mathrm{~m}$ \\
$\nu(\mathrm{C}=\mathrm{S})$ & $1143 \mathrm{~m}$ & $1133 \mathrm{~m}$ \\
Thioamide II & $1320 \mathrm{~s}$ & $1305 \mathrm{~s}$ \\
Thioamide III & $1075 \mathrm{~m}$ & $1051 \mathrm{w}$ \\
Thioamide IV & $639 \mathrm{w}$ & $650 \mathrm{w}$ \\
\hline
\end{tabular}

carbonyl stretching, in the IR-spectrum of $\mathrm{Hg}(\mathrm{Hmna})_{2}$ at $1686 \mathrm{~cm}^{-1}$, clearly indicates that the carboxyl group 
Table 3. ${ }^{1} \mathrm{H}$ and ${ }^{13} \mathrm{C}$ NMR chemical shifts $(\delta / \mathrm{ppm}){ }^{\mathrm{a}}, \mathrm{H}-\mathrm{H}$ and $\mathrm{C}-\mathrm{H}$ coupling constants $(\mathrm{J} / \mathrm{Hz})^{\mathrm{b}}$ and difference in chemical shifts $(\Delta \delta / \mathrm{ppm})^{\mathrm{c}}$ in thiol and thione tautomers of $\mathrm{H}_{2}$ mna

\begin{tabular}{|c|c|c|c|}
\hline $\begin{array}{l}\text { Molecule } \\
\text { Atom }\end{array}$ & & Thiol (TL) & Thione (TN) \\
\hline H-4 & $\begin{array}{l}\delta \\
J_{\mathrm{HH}} \\
\Delta \delta\end{array}$ & $\begin{array}{l}8.26(1) \\
6.8(d)\end{array}$ & $\begin{array}{l}8.52(1) \\
6.2(d) \\
-0.26\end{array}$ \\
\hline H-5 & $\begin{array}{l}\delta \\
J_{\mathrm{HH}} \\
\Delta \delta\end{array}$ & $\begin{array}{l}7.29 \text { (1) } \\
7.5 \text { (d) }\end{array}$ & $\begin{array}{l}7.13(1) \\
6.8(d) \\
0.16\end{array}$ \\
\hline H-6 & $\begin{array}{l}\delta \\
J_{\mathrm{HH}} \\
\Delta \delta\end{array}$ & $\begin{array}{l}8.52(1) \\
4.8(d)\end{array}$ & $\begin{array}{l}8.15(1) \\
4.8(d) \\
0.37\end{array}$ \\
\hline NH & $\begin{array}{l}\delta \\
J_{\mathrm{HH}} \\
\Delta \delta\end{array}$ & n.e. $^{\mathrm{d}}$ & $\begin{array}{l}14.57(1) \\
\mathrm{s}\end{array}$ \\
\hline $\mathrm{COOH}$ & $\begin{array}{l}\delta \\
J_{\mathrm{HH}} \\
\Delta \delta\end{array}$ & $\begin{array}{l}14.57(1) \\
\mathrm{s}\end{array}$ & $\begin{array}{l}14.57(1) \\
\mathrm{s}\end{array}$ \\
\hline SH & $\begin{array}{l}\delta \\
J_{\mathrm{HH}} \\
\Delta \delta\end{array}$ & $\begin{array}{l}4.63(1) \\
s\end{array}$ & n.e. $^{\mathrm{d}}$ \\
\hline $\mathrm{C}-2$ & $\begin{array}{l}\delta \\
J_{\mathrm{CH}} \\
\Delta \delta\end{array}$ & $\begin{array}{l}159.21 \\
\mathrm{~s}\end{array}$ & $\begin{array}{l}173.62 \\
\mathrm{~s} \\
-14.41\end{array}$ \\
\hline $\mathrm{C}-3$ & $\begin{array}{l}\delta \\
J_{\mathrm{CH}} \\
\Delta \delta\end{array}$ & $\begin{array}{l}124.54 \\
\mathrm{~s}\end{array}$ & $\begin{array}{l}129.87 \\
\mathrm{~s} \\
-5.33\end{array}$ \\
\hline C-4 & $\begin{array}{l}\delta \\
J_{\mathrm{CH}} \\
\Delta \delta\end{array}$ & $\begin{array}{l}139.50 \\
167.7 \text { (d) }\end{array}$ & $\begin{array}{l}144.32 \\
167.1(\mathrm{~d}) \\
-4.82\end{array}$ \\
\hline C-5 & $\begin{array}{l}\delta \\
J_{\mathrm{CH}} \\
\Delta \delta\end{array}$ & $\begin{array}{l}120.90 \\
168.9 \text { (d) }\end{array}$ & $\begin{array}{l}115.41 \\
176.5(d) \\
5.49\end{array}$ \\
\hline C-6 & $\begin{array}{l}\delta \\
J_{\mathrm{CH}} \\
\Delta \delta\end{array}$ & $\begin{array}{l}152.73 \\
182.8(\mathrm{~d})\end{array}$ & $\begin{array}{l}143.58 \\
187.6(d) \\
9,15\end{array}$ \\
\hline $\mathrm{COOH}$ & $\begin{array}{l}\delta \\
J_{\mathrm{CH}} \\
\Delta \delta\end{array}$ & $\begin{array}{l}167.30 \\
\mathrm{~s}\end{array}$ & $\begin{array}{l}165.71 \\
\mathrm{~s} \\
1,59\end{array}$ \\
\hline
\end{tabular}

${ }^{a}$ Recorded in DMSO-d $\mathrm{d}_{6}$ solution. Referred to TMS. Number of protons in brackets.

b (s) singlet, (d) doublet

${ }^{\mathrm{c}}$ Sign $(+)$ denotes deshielding effect, while $(-)$ denotes shielding effects.

${ }^{\mathrm{d}}$ Not existing proton in thiol or thione tautomer.

remained protonated and therefore is not coordinated to the mercury atom. Low wavenumbers of the $v(\mathrm{C}=\mathrm{O})$ carbonyl stretching bands in the IR spectra of free $\mathrm{H}_{2}$ mna and $\mathrm{Hg}(\mathrm{Hmna})_{2}\left(1688 \mathrm{~cm}^{-1}\right.$ and $1686 \mathrm{~cm}^{-1}$, respectively) are probably caused by hydrogen bonding
Table 4. ${ }^{1} \mathrm{H}$ and ${ }^{13} \mathrm{C}$ NMR chemical shifts $(\delta / \mathrm{ppm}){ }^{\mathrm{a}}, \mathrm{H}-\mathrm{H}$ and $\mathrm{C}-\mathrm{H}$ coupling constants $(\mathrm{J} / \mathrm{Hz})^{\mathrm{b}}$ and difference in the chemical shifts $(\Delta \delta / \mathrm{ppm})^{\mathrm{c}}$ of bis(pyridine-3-carboxy-2thiolato-S)mercury and the thiol form of $\mathrm{H}_{2} \mathrm{mna}$

\begin{tabular}{llll}
\hline Atom & $\delta / \mathrm{ppm}$ & $J / \mathrm{Hz}$ & $\Delta \delta_{\mathrm{TL}}{ }^{\mathrm{d}}$ \\
\hline $\mathbf{H}-4$ & $8.12(1)$ & $7.7(\mathrm{~d})$ & -0.14 \\
$\mathbf{H}-5$ & $7.17(1)$ & $7.7(\mathrm{~d})$ & -0.12 \\
$\mathbf{H}-6$ & $8.32(1)$ & $4.8(\mathrm{~d})$ & -0.20 \\
$\mathbf{C O O H}$ & $13.24(1)$ & $\mathrm{s}$ & 0 \\
$\mathbf{C - 2}$ & 165.50 & $12.8(\mathrm{~d})$ & 6.29 \\
$\mathbf{C - 3}$ & 126.32 & $6.7(\mathrm{~d})$ & 1.78 \\
$\mathbf{C - 4}$ & 139.62 & $166.4(\mathrm{~d})$ & 0.12 \\
$\mathbf{C - 5}$ & 119.77 & $168.9(\mathrm{~d})$ & -1.13 \\
$\mathbf{C - 6}$ & 150.57 & $182.8(\mathrm{~d})$ & -2.16 \\
COOH & 167.21 & $\mathrm{~s}$ & -0.09 \\
\hline
\end{tabular}

${ }^{\mathrm{a}}$ Recorded in DMSO- $\mathrm{d}_{6}$ solution. Referred to TMS. Number of protons in brackets.

b (s) singlet, (d) doublet

${ }^{\mathrm{c}}$ Sign $(+)$ denotes deshielding effect, while $(-)$ denotes shielding effects.

${ }^{\mathrm{d}} \Delta \delta_{\mathrm{TL}}$ means difference between chemical shifts of the complex and the ligand in thiol (TL) form.

in the crystal structure of the compounds. Disappearance of the $\delta(\mathrm{N}-\mathrm{H})$ band $\left(1621 \mathrm{~cm}^{-1}\right)$ in the IRspectrum of $\mathrm{Hg}(\mathrm{Hmna})_{2}$ indicates that the thiolate is bound to the metal ion. ${ }^{40}$ The thioamide bands I and II are shifted to a lower wavenumber in the IR-spectrum of $\mathrm{Hg}(\mathrm{Hmna})_{2}$ indicating that the nitrogen atom does not participate in coordination. ${ }^{7}$ The thioamide band III at $1075 \mathrm{~cm}^{-1}$ shifts to a lower wavenumber upon coordination $\left(1051 \mathrm{~cm}^{-1}\right)$. The most significant change has been observed for the thioamide band III and $v(\mathrm{C}=\mathrm{S})$, supporting coordination through the ligand sulphur atom. ${ }^{10,41}$

Information on the $\mathrm{Hg}-\mathrm{S}$ vibrational modes can be obtained from low frequency Raman spectra. The frequency range of the Raman active $\mathrm{Hg}-\mathrm{S}$ stretching vibration for mercury(II) thiolates is $400-180 \mathrm{~cm}^{-1}$. $^{42}$ Position of the $\mathrm{Hg}-\mathrm{S}$ stretching mode depends on the coordination number of mercury. In the Raman spectrum of $\mathrm{Hg}(\mathrm{Hmna})_{2}$ the medium band at $378 \mathrm{~cm}^{-1}$ is observed. This band can be assigned to a $v(\mathrm{Hg}-\mathrm{S})$ stretching vibration. One Raman active stretching mode is consistent with the linear coordination of mercury(II). The medium band at $175 \mathrm{~cm}^{-1}$ can be tentatively assigned to $\delta(\mathrm{S}-\mathrm{Hg}-\mathrm{S})$ bending.

Assignment of the NMR spectra of the free ligand in both tautomeric forms and its mercury(II) complex are shown in Tables 3 and 4, respectively. The enumeration of carbon atoms are displayed in Scheme 1.

Signals in the ${ }^{1} \mathrm{H}$ NMR spectra of 2-mercaptonicotinic acid in DMSO- $\mathrm{d}_{6}$ correspond to the thione tautomer form, what is in agreement with literature 
data $^{43}$ for similar compounds. The very broad ${ }^{1} \mathrm{H}$ signal belongs to both $\mathrm{NH}$ and $\mathrm{COOH}$ protons of 2-mercaptonicotinic acid. This was proven by addition of a small amount of $\mathrm{Na}_{2} \mathrm{CO}_{3}$ which neutralizes the acid and interrupts the hydrogen bonding as was revealed by an upfield shift of the NH proton.

The thiol form appears after a few weeks in a DMSO- $\mathrm{d}_{6}$ solution or immediately by addition of $\mathrm{HCl}$.

As expected, the chemical shifts of thiol and thione forms are different. The shielding effect of the $\mathrm{C}=\mathrm{S}$ group upon the $\mathrm{H}-5$ atom in the thione form is greater than that of the $\mathrm{C}-\mathrm{SH}$ group upon $\mathrm{H}-5$ atom in the thiol form, both being in the para position to the H-5.

The chemical shifts $(\delta / \mathrm{ppm})$ and the $\mathrm{C}-\mathrm{H}$ coupling constants $\left(J_{\mathrm{CH}} / \mathrm{Hz}\right)$ in ${ }^{13} \mathrm{C}$ NMR spectra of 2-mercaptonicotinic acid in DMSO- $\mathrm{d}_{6}$ solution also correspond to the thione form. Two-bond deuterium isotope effect from $\mathrm{N}-\mathrm{D}$ to $\mathrm{C}-6$ is observed, amounting to $40 \mathrm{ppb}$, while four-bond deuterium isotope effect on the carboxyl carbon atom is not detected.

The ${ }^{1} \mathrm{H}$ and ${ }^{13} \mathrm{C}$ NMR spectra of bis(pyridine-3carboxy-2-thiolato- $S$ )mercury(II), $\quad \mathrm{Hg}(\mathrm{Hmna})_{2}$ in DMSO- $\mathrm{d}_{6}$ solution are similar to the spectra of the ligand molecule in the thiol form, which corroborates that the ligand in the mercury complex is in the thiol rather than in the thione form. The NMR data display that both a number of hydrogen and carbon atoms in complex are sensitive to mercury binding. ${ }^{44}$ Thus in the mercury complex the $\mathrm{COOH}$ proton is shifted upfield, which can be clearly seen since there is no $\mathrm{NH}$ proton in the thiol form to overlap with $\mathrm{COOH}$. A considerable downfield shift, amounting to $6.3 \mathrm{ppm}$ at the $\mathrm{C}-2$ carbon in $\mathrm{Hg}(\mathrm{Hmna})_{2}$ and upfield shifts at C-6 and C-5 atoms, with the fact that the chemical shift of the $\mathrm{COOH}$ carbon barely changed, is consistent with $S$-bonded ligand to mercury. In the case of $N, S$-chelation, a downfield shift of C-6 should be observed., ${ }^{7,9}$

\section{Thermal Analysis}

TG and DSC analysis of $\mathrm{H}_{2}$ mna and $\mathrm{Hg}(\mathrm{Hmna})_{2}$ were also performed. The samples were heated from room temperature to $600{ }^{\circ} \mathrm{C}(\mathrm{TG})$ and from room temperature to $500{ }^{\circ} \mathrm{C}$ (DSC). TG curve of $\mathrm{H}_{2}$ mna show two degradation steps. Small mass loss (approx. $5 \%$ ) due to the sublimation of $\mathrm{H}_{2} \mathrm{mna}$ is observed in the first step. This step is represented by an endothermic peak at $233{ }^{\circ} \mathrm{C}$ on the DSC curve. Endothermic minima at $261{ }^{\circ} \mathrm{C}$ with a corresponding mass loss of $90 \%$ represents almost complete degradation of $\mathrm{H}_{2} \mathrm{mna}$. Degradation of $\mathrm{Hg}(\mathrm{Hmna})_{2}$ proceeds over two overlapping steps in the range $253-555{ }^{\circ} \mathrm{C}$. The first step corresponding to the elimination of both ligands without the sulphur atoms is represented by two endothermic DSC peaks at 254 and $261{ }^{\circ} \mathrm{C}$. A broad endothermic peak at $408{ }^{\circ} \mathrm{C}$ on the DSC curve of $\mathrm{Hg}(\mathrm{Hmna})_{2}$ corresponds to the thermal

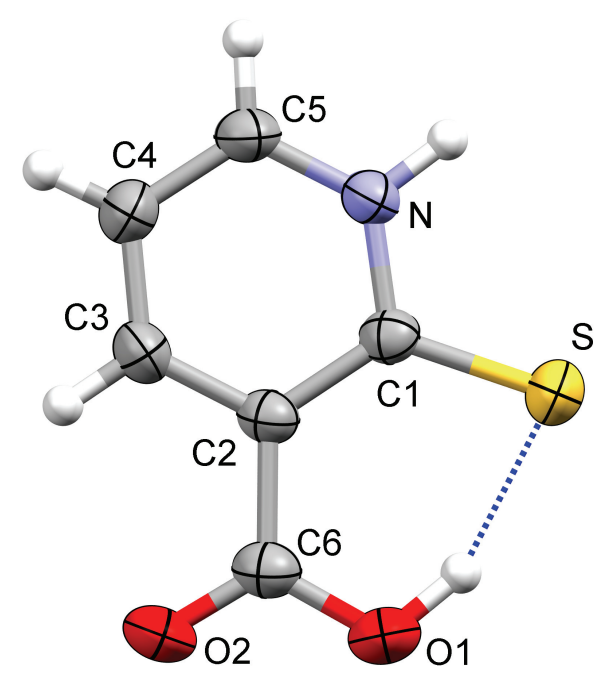

Figure 1. Molecular structure of 2-mercaptonicotinic acid, $\mathrm{H}_{2}$ mna, showing the atom numbering scheme. Displacement ellipsoids are drawn at the $50 \%$ probability level. Hydrogen atoms are drawn as small circles of arbitrary radius. The intramolecular hydrogen bond is shown as a blue dashed line.

degradation of $\mathrm{HgS}$ followed by evaporation of mercury.

\section{Crystal Structure of $\mathrm{H}_{2}$ mna}

2-mercaptonicotinic acid (Scheme 1, Figure 1) exists in the crystalline state in the thione tautomeric form as it was previously established by vibrational spectroscopy according to the absence of the SH vibration characteristic for the thiol form, by the presence of the NH vibration band ${ }^{9}$ and also from the previously reported crystal structure. ${ }^{10}$ The thione tautomer is established to be the dominant form in the crystalline state for heterocyclic thiones.

Bond distances and valence angles are given in Tables 5 and 6 , respectively. The molecule is planar with the greatest deviation of the atom O2 of $0.059(2) \AA$

Table 5. Selected bond distances $/ \AA$ in $\mathrm{H}_{2} \mathrm{mna}$ and $\mathrm{HgBr}_{2}\left(\mathrm{CH}_{3}-\mathrm{Hmna}\right)_{2}$

\begin{tabular}{llll}
\hline \multicolumn{4}{c}{$\mathbf{H}_{2} \mathbf{m n a}$} \\
\hline $\mathrm{O} 1-\mathrm{C} 6$ & $1.321(3)$ & $\mathrm{S}-\mathrm{C} 1$ & $1.7034(18)$ \\
$\mathrm{O} 2-\mathrm{C} 6$ & $1.217(3)$ & $\mathrm{N}-\mathrm{C} 1$ & $1.369(3)$ \\
& \multicolumn{4}{c}{$\mathrm{N}-\mathrm{C} 5$} & $1.343(3)$ \\
\hline \multicolumn{4}{c}{$\mathbf{H g B r}_{2}\left(\mathbf{C H}_{3}-\mathrm{Hmna}\right)_{2}$} \\
\hline $\mathrm{Hg}-\mathrm{Br}$ & $2.7602(7)$ & $\mathrm{S}-\mathrm{C} 1$ & $1.710(6)$ \\
$\mathrm{Hg}-\mathrm{S}$ & $2.4587(14)$ & $\mathrm{N}-\mathrm{C} 1$ & $1.366(7)$ \\
$\mathrm{O} 1-\mathrm{C} 6$ & $1.188(7)$ & $\mathrm{N}-\mathrm{C} 5$ & $1.330(7)$ \\
$\mathrm{O} 2-\mathrm{C} 6$ & $1.331(6)$ & & \\
$\mathrm{O} 2-\mathrm{C} 7$ & $1.465(8)$ & \\
\hline
\end{tabular}


Table 6. Selected bond angles ${ }^{\circ}$ in $\mathrm{H}_{2} \mathrm{mna}$ and $\mathrm{HgBr}_{2}\left(\mathrm{CH}_{3}-\mathrm{Hmna}\right)_{2}$

\begin{tabular}{llll}
\hline \multicolumn{5}{c}{$\mathbf{H}_{2} \mathbf{m n a}$} \\
$\mathrm{C} 1-\mathrm{N}-\mathrm{C} 5$ & $125.03(19)$ & $\mathrm{S}-\mathrm{C} 1-\mathrm{C} 2$ & $127.60(18)$ \\
$\mathrm{N}-\mathrm{C} 1-\mathrm{C} 2$ & $115.43(17)$ & $\mathrm{S}-\mathrm{C} 1-\mathrm{N}$ & $116.97(17)$ \\
$\mathrm{N}-\mathrm{C} 5-\mathrm{C} 4$ & $120.2(2)$ & $\mathrm{O} 1-\mathrm{C} 6-\mathrm{C} 2$ & $118.87(19)$ \\
& & $\mathrm{O} 2-\mathrm{C} 6-\mathrm{C} 2$ & $121.33(19)$ \\
& $\mathrm{O} 1-\mathrm{C} 6-\mathrm{O} 2$ & $119.8(2)$ \\
\hline \multicolumn{5}{c}{$\mathbf{H g B r}_{2}\left(\mathbf{C H}_{3}-\mathrm{Hmna}\right)_{2}$} \\
\hline $\mathrm{Br}-\mathrm{Hg}-\mathrm{S}$ & $100.35(4)$ & $\mathrm{S}-\mathrm{C} 1-\mathrm{C} 2$ & $124.8(4)$ \\
$\mathrm{Br}-\mathrm{Hg}-\mathrm{Br}^{i}$ & $98.87(2)$ & $\mathrm{S}-\mathrm{C} 1-\mathrm{N}$ & $120.6(3)$ \\
$\mathrm{Br}-\mathrm{Hg}-\mathrm{S}^{i}$ & $110.87(4)$ & $\mathrm{O} 1-\mathrm{C} 6-\mathrm{C} 2$ & $126.2(5)$ \\
$\mathrm{S}-\mathrm{Hg}-\mathrm{S}^{i}$ & $131.33(5)$ & $\mathrm{O} 2-\mathrm{C} 6-\mathrm{C} 2$ & $110.0(5)$ \\
$\mathrm{Hg}-\mathrm{S}-\mathrm{C} 1$ & $110.01(18)$ & $\mathrm{O} 1-\mathrm{C} 6-\mathrm{O} 2$ & $123.8(5)$ \\
$\mathrm{C} 1-\mathrm{N}-\mathrm{C} 5$ & $125.7(4)$ & $\mathrm{C} 6-\mathrm{O} 2-\mathrm{C} 7$ & $115.3(5)$ \\
$\mathrm{N}-\mathrm{C} 1-\mathrm{C} 2$ & $114.7(5)$ & & \\
$\mathrm{N}-\mathrm{C} 5-\mathrm{C} 4$ & $120.4(5)$ & & \\
\hline
\end{tabular}

${ }^{i}$ Symmetry transformation used to generate equivalent atoms: (i) $3 / 2-x, 1 / 2-y, z$

from the least-squares plane through the ring atoms. The $\mathrm{C}_{\mathrm{ar}}-\mathrm{S}$ bond distance of 1.703(2) $\AA$ corresponds to a $\mathrm{C}-\mathrm{S}$ bond of significant $\pi$-character within the structures of heterocyclic thiones (the average value is $1.671 \AA$ for the $\mathrm{Csp}^{2}=\mathrm{S}$ bond distance type in the structural fragment $(\mathrm{X})_{2}-\mathrm{C}=\mathrm{S}$ where $\left.\mathrm{X}=\mathrm{C}, \mathrm{N}, \mathrm{O}, \mathrm{S}\right)^{34}$ and can be regarded as a thioketo bond. According to the literature ${ }^{45}$ the bond length of 1.703(2) $\AA$ possesses $50 \%$ of $\pi$ character. The pyridine ring $\mathrm{C}_{\mathrm{ar}}-\mathrm{C}_{\mathrm{ar}}$ bond lengths exhibit a quinoid character with the longest $\mathrm{C} 1-\mathrm{C} 2$ bond

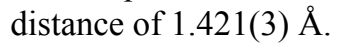

Hydrogen bond geometry is listed in Table 7 . The thione $\mathrm{S}$ atom forms a six-membered pseudo-aromatic chelate ring by an intramolecular hydrogen bond of the $\mathrm{O}-\mathrm{H} \cdots \mathrm{S}$ type with the $\mathrm{OH}$ group of the carboxyl moiety $(2.895(2) \AA)$. The molecules are connected by the intermolecular $\mathrm{N}-\mathrm{H} 1 \cdots \mathrm{O} 2(1 / 2+x, 1 / 2-y,-1+z)$ hydrogen bonds into infinite chains (Figure 2) spreading parallel to the [102] direction alternating along the $b$-axis (shifted by $b / 2$ ) with chains parallel to the [10-2] direction. The formation of such intra- and intermolecular

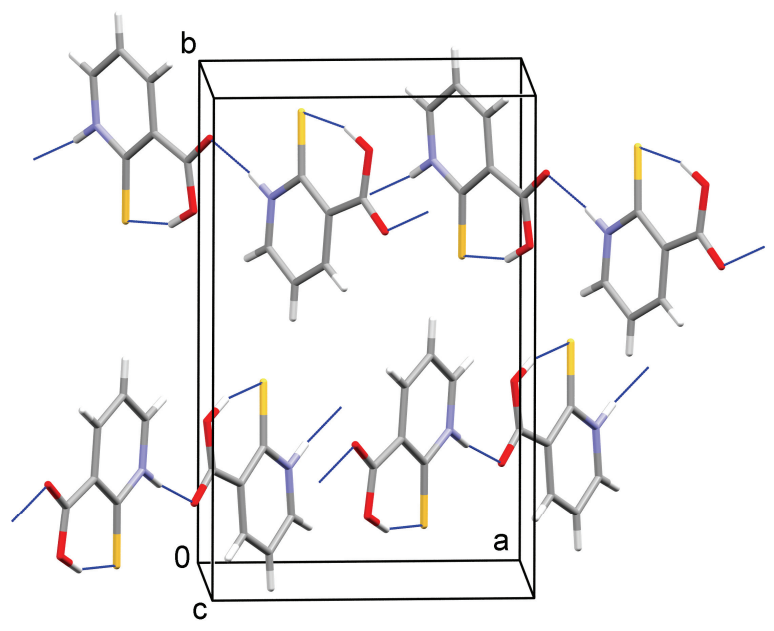

Figure 2. $\mathrm{H}_{2}$ mna molecules connected into chains by hydrogen bonds. The dotted blue lines indicate intramolecular $\mathrm{O} 1-\mathrm{H} \cdots \mathrm{S}$ and intermolecular $\mathrm{N}-\mathrm{H} \cdots \mathrm{O} 2^{i}(i=1 / 2+x, 1 / 2-y$, $-1+z$ ) hydrogen bonds.

hydrogen bonds compensate the energetically less favoured thione form. Namely, the SH group is less acidic than the $\mathrm{NH}$ group i.e. it is not such a good proton donor group in the hydrogen bond formation.

\section{Crystal Structure of $\mathrm{HgBr}_{2}\left(\mathrm{CH}_{3}-\mathrm{Hmna}\right)_{2}$}

In the crystal structure of $\mathrm{HgBr}_{2}\left(\mathrm{CH}_{3}-\mathrm{Hmna}\right)_{2}$ the mercury atom lies on a two-fold axis and is coordinated by two sulphur atoms from two 3-metoxycarbonylpyridine-2-thiolato ligands and by two bromine atoms in a deformed tetrahedral arrangement (Figure 3, Tables 5 and 6). The smallest angle within the tetrahedron is that of $\mathrm{Br}-\mathrm{Hg}-\mathrm{Br}(3 / 2-x, 1 / 2-y, z)$ of $98.87(2)^{\circ}$, while the greatest one is $\mathrm{S}-\mathrm{Hg}-\mathrm{S}(3 / 2-x, 1 / 2-y, z)$ of $131.33(5)^{\circ}$. The Cambridge Structural Database ${ }^{46}$ search gave 28 structures with the mercury atom tetrahedrally coordinated by two sulphur atoms and two bromine atoms. In these structures the bond lengths vary significantly and appear in a wide range, $\mathrm{Hg}-\mathrm{S} 2.45$ to $3.19 \AA$ and $\mathrm{Hg}-\mathrm{Br}$ 2.38 to $3.01 \AA$. In the present structure the $\mathrm{Hg}-\mathrm{S}$

Table 7. Hydrogen bonds in $\mathrm{H}_{2}$ mna and $\mathrm{HgBr}_{2}\left(\mathrm{CH}_{3}-\mathrm{Hmna}\right)_{2}$

\begin{tabular}{|c|c|c|c|c|c|}
\hline $\mathrm{D}-\mathrm{H} \cdots \mathrm{A}$ & $\mathrm{D}-\mathrm{H} / \AA$ & $\mathrm{H} \cdots \mathrm{A} / \AA$ & $\mathrm{D} \cdots \mathrm{A} / \AA$ & $\angle \mathrm{D}-\mathrm{H} \cdots \mathrm{A} /{ }^{\circ}$ & Symmetry code \\
\hline \multicolumn{6}{|c|}{$\mathrm{H}_{2} \mathrm{mna}$} \\
\hline $\mathrm{N}-\mathrm{H} 1 \cdots \mathrm{O} 2$ & $0.94(3)$ & $1.88(3)$ & $2.813(3)$ & $172(2)$ & \\
\hline $\mathrm{O} 1-\mathrm{H} 1 \cdots \mathrm{S}$ & $0.97(3)$ & $1.98(3)$ & $2.8952(19)$ & $157(3)$ & \\
\hline $\mathrm{C} 5-\mathrm{H} 5 \cdots \mathrm{O} 1$ & 0.93 & 2.567 & $3.279(3)$ & 134 & $1 / 2+x, 1 / 2-y,-1+z$ \\
\hline \multicolumn{6}{|c|}{$\mathrm{HgBr}_{2}\left(\mathrm{CH}_{3}-\mathrm{Hmna}\right)_{2}$} \\
\hline $\mathrm{N}-\mathrm{H} 1 \cdots \mathrm{Br}$ & 0.86 & 2.43 & $3.274(4)$ & 167 & \\
\hline $\mathrm{C} 5-\mathrm{H} 5 \cdots \mathrm{O} 1$ & 0.93 & 2.48 & $3.245(8)$ & 140 & $5 / 4-x, 1 / 4+y, 5 / 4+z$ \\
\hline
\end{tabular}




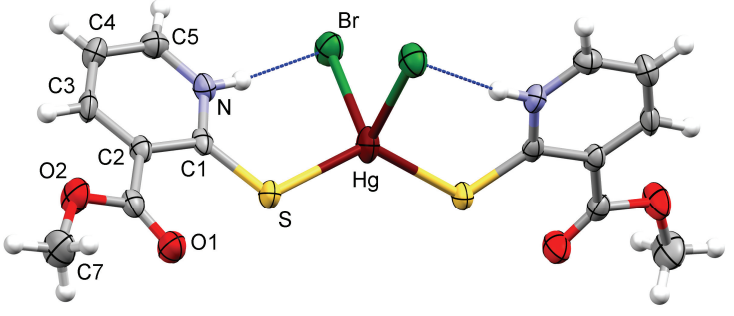

Figure 3. Molecular structure of $\mathrm{HgBr}_{2}\left(\mathrm{CH}_{3}-\mathrm{Hmna}\right)_{2}$, showing the atom numbering scheme. Displacement ellipsoids are drawn at the $50 \%$ probability level. Hydrogen atoms are drawn as small circles of arbitrary radius. Intramolecular hydrogen bonds are shown as blue dotted lines.

distance of $2.4587(14) \AA$ is among the shortest values. This bond distance is shorter than the sum of covalent radii of $\mathrm{S}$ and tetrahedral $\mathrm{Hg}(2.53 \AA)$ but longer than the linear $\mathrm{Hg}-\mathrm{S}$ bond $(2.34 \AA) .{ }^{47,48}$ Similar values we have observed previously ${ }^{18}$ in the structure of dibromobis(1,3-imidazole-2-thione), (Hg-S 2.453(2) $\AA, \mathrm{Hg}-\mathrm{Br}$ 2.7815(9) $\AA, \quad \mathrm{S}-\mathrm{Hg}-\mathrm{S} \quad 134.80(10)^{\circ}$ and $\mathrm{Br}-\mathrm{Hg}-\mathrm{Br}$ $\left.95.25(4)^{\circ}\right)$ and in dibromobis $(3,4,5,6$-tetrahydropyrimidine-2-thione) ${ }^{21}$ (Hg-S 2.431(2) and 2.467(2) $\AA$, $\mathrm{Hg}-\mathrm{Br} 2.734(1)$ and $2.732(1) \AA, \mathrm{S}-\mathrm{Hg}-\mathrm{S} 138.82^{\circ}$, $\left.\mathrm{Br}-\mathrm{Hg}-\mathrm{Br} 105.56(3)^{\circ}\right)$. In dibromobis(1,3-benzothiazole-2-thione)mercury(II) ${ }^{26}$ the two $\mathrm{Hg}-\mathrm{Br}$ distances are significantly different with the bromine atom forming the longer bond being involved in hydrogen bonding $(\mathrm{Hg}-\mathrm{Br} 2.758(1)$ and 2.546(2) $\AA, \mathrm{Hg}-\mathrm{S} 2.493(3)$ and 2.494(3) $\AA, \quad \mathrm{S}-\mathrm{Hg}-\mathrm{S}$ of $124.42(10)^{\circ}, \quad \mathrm{Br}-\mathrm{Hg}-\mathrm{Br}$ $\left.113.63(4)^{\circ}\right)$. In the present structure the bromine atoms are involved in intramolecular hydrogen bonding (Table 7, Figure 4). There are only weak contacts of the $\mathrm{C}-\mathrm{H} \cdots \mathrm{O}$ type between the molecules.

The $\mathrm{Csp}^{2}-\mathrm{S}$ bond distance of $1.710(6) \AA$ is lengthened in relation to the distance found in free $\mathrm{H}_{2}$ mna due to metal coordination. The lengthening is caused by reduction of the $\pi$ character of the $\mathrm{C}-\mathrm{S}$ bond. The $\mathrm{CH}_{3}$-Hmna ligand is more distorted from planarity, the deviation of the atom O2 is 0.298(4) $\AA$ from the least-squares plane through the ring atoms.

\section{CONCLUSION}

The reaction of 2-mercaptonicotinic acid with various mercury(II) salts, $\mathrm{HgX}_{2}\left(\mathrm{X}=\mathrm{Cl}^{-}, \mathrm{Br}^{-}, \mathrm{I}^{-}, \mathrm{SCN}^{-}\right)$in an ethanol or methanol solution irrespectively of the molar ratio of the reactants $(1: 1$ or $1: 2)$ resulted in the mercury complex, $\mathrm{Hg}(\mathrm{Hmna})_{2}$, with two ligands of 2mercaptonicotinic acid linearly bound through the Satom. The same compound was obtained from the reaction of mercury(II) acetate in an aqueous-ethanol solution.

The absence of the $v(\mathrm{~S}-\mathrm{H})$ absorption at 2500 $\mathrm{cm}^{-1}$ in the IR-spectrum of the free $\mathrm{H}_{2} \mathrm{mna}$, and pres-

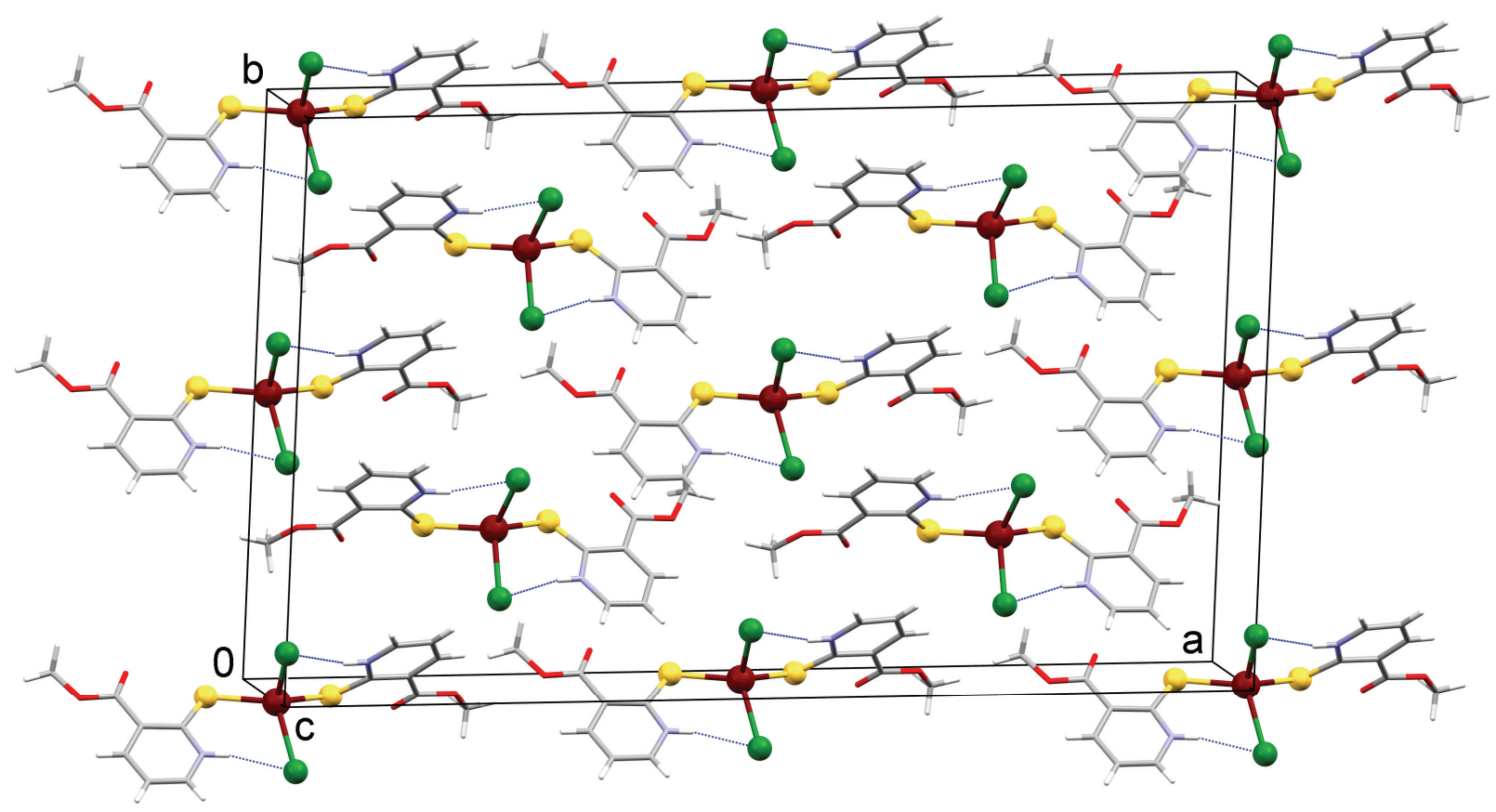

Figure 4. Packing of $\mathrm{HgBr}_{2}\left(\mathrm{CH}_{3}-\mathrm{Hmna}\right)_{2}$ molecules in the unit cell. The dotted blue lines indicate intramolecular $\mathrm{N}-\mathrm{H} \cdots \mathrm{Br}$ hydrogen bonds. 
ence of the $v(\mathrm{~N}-\mathrm{H})$ band at $3187 \mathrm{~cm}^{-1}$ and $v(\mathrm{C}=\mathrm{S})$ band at $1143 \mathrm{~cm}^{-1}$ indicates that the $\mathrm{H}_{2} \mathrm{mna}$ exists as thione tautomer in the solid state as revealed by the $\mathrm{X}$-ray structure analysis. ${ }^{1} \mathrm{H}$ and ${ }^{13} \mathrm{C}$ NMR spectra of the free $\mathrm{H}_{2} \mathrm{mna}$ confirm that the thione form is the dominant form in the DMSO solution. The thiol form forms after a few weeks in a DMSO- $\mathrm{d}_{6}$ solution or immediately by addition of $\mathrm{HCl}$. $\mathrm{HgBr}_{2}\left(\mathrm{CH}_{3}-\mathrm{Hmna}\right)_{2}$ was obtained from the reaction of $\mathrm{H}_{2}$ mna with $\mathrm{HgBr}_{2}$ in methanol after filtering off the main product $\mathrm{Hg}(\mathrm{Hmna})_{2}$. The crystal structure of $\mathrm{HgBr}_{2}\left(\mathrm{CH}_{3}-\mathrm{Hmna}\right)_{2}$ revealed a tetrahedral coordination sphere around the mercury atom consisting of two bromine atoms and two S-bound 3-metoxycarbonylpyridine-2-thiolato ligands. IR and NMR spectroscopic data are consistent with coordination of the $\mathrm{H}_{2}$ mna through sulphur atom in the solid state, and also in the DMSO solution of the $\mathrm{Hg}(\mathrm{Hmna})_{2}$.

Supplementary Materials. - The crystallographic data have been deposited with the Cambridge Crystallographic Data Center as supplementary material with the deposition numbers: CCDC 649287 for $\mathrm{H}_{2}$ mna and CCDC 891562 for $\mathrm{HgBr}_{2}\left(\mathrm{CH}_{3}-\mathrm{Hmna}\right)_{2}$. Copies of the data can be obtained free of charge via http:/www.ccdc.cam.ac.uk/const/retrieving.html.

Acknowledgements. This work was supported by the Ministry of Science, Education and Sports of the Republic of Croatia, Zagreb within the scientific projects under the titles "Chemistry of metal complexes in reactions of biological importance and new materials" (No. 119-1193079-1332), "X-ray structural studies of biological macromolecules" (1191193079-1084), and in the framework of the scientific programme "Ligands, complexes, proteins - synthesis and structure - properties relationship" and "NMR spectroscopy and modelling of bioactive molecules" scientific project (No. 0980982929-2917) in the framework of the program "Spectroscopy and modelling of bioactive molecules".

\section{REFERENCES}

1. T. L. Blundell and J. Jenkins, Chem. Soc. Rev. (1977) 139-171.

2. R. G. Pearson, J. Am. Chem. Soc. 85 (1963) 3533-3539.

3. R. G. Pearson, J. Chem. Educ. 45 (1968) 581-587.

4. J. G. Wright, M. J. Natan, F. M. MacDonnell, D. M. Ralston, and T. V. O'Halloran, Prog. Inorg. Chem. 38 (1990) 323-412.

5. K. A. Idriss, M. S. Saleh, H. A. Azab, and E. Y. Hashem, Bull. Polish Acad. Sci. 43 (1995) 67-73.

6. F. N. Rein and H. E. Toma, Polyhedron 17 (1998) 1439-1448.

7. S. Marchal, V. Moreno, G. Aullón, S. Alvarez, M. Quiros, M. Font-Bardia, and X. Solans, Polyhedron 18 (1999) 3675-3682.

8. K. Nomiya, S. Takahashi, and R. Noguchi, J. Chem. Soc. Dalton Trans. (2000) 2091-2097.

9. S. M. O. Quintal, H. I. S. Nogueira, V. Félix, and M. G. B. Drew, J. Chem. Soc. Dalton Trans. (2002) 4479-4487.

10. P. C. Zachariadis, S. K. Hadjikakou, N. Hadjiliadis, A. Michaelides, S. Skoulika, Y. Ming, and Y. Xiaolin, Inorg. Chim. Acta 343 (2003) 361-365.

11. S. M. Humphrey, R. A. Mole, J. M. Rawson, and P. T. Wood, Dalton Trans. (2004) 1670-1678.
12. S. M. Humphrey, A. Alberola, C. J. Gómez García, and P. T. Wood, Chem. Comm. (2006) 1607-1609.

13. Q. Yang, S. Chen, and S. Gao, J. Therm. Anal. Cal. 90 (2007) 881-885.

14. S.-P. Chen, Q. Yang, and S. Gao, J. Therm. Anal. Cal. 95 (2009) 685-689.

15. G. Rabbani, A. A. Isab, A. R. Al-Arfaj, S. Ahmad, M. Saleem, A. Hameed, and E. Akbar, Spectroscopy 23 (2009) 45-50.

16. S. M. S. Haggag, Eur. J. Inorg. Chem. (2010) 1572-1580.

17. Z. Popović, D. Matković-Čalogović, J. Hasić, and D. VikićTopić, Inorg. Chim. Acta 285 (1999) 208-216.

18. Z. Popović, D. Matković-Čalogović, Ž. Soldin, G. Pavlović, N. Davidović, and D. Vikić-Topić, Inorg. Chim. Acta 294 (1999) 35-46.

19. G. Pavlović, Z. Popović, Ž. Soldin, and D. Matković-Čalogović, Acta Crystallogr. C56 (2000) 61-63.

20. G. Pavlović, Z. Popović, Ž. Soldin, and D. Matković-Čalogović, Acta Crystallogr. C56 (2000) 801-803.

21. Z. Popović, D. Matković-Čalogović, G. Pavlović, Ž. Soldin, M. Rajić, D. Vikić-Topić, and D. Kovaček, Inorg. Chim. Acta 306 (2000) 142-152.

22. Z. Popović, D. Matković-Čalogović, G. Pavlović, Ž. Soldin, G. Giester, M. Rajić, and D. Vikić-Topić, Croat. Chem. Acta $\mathbf{7 4}$ (2001) 359-390.

23. D. Matković-Čalogović, Z. Popović, G. Pavlović, Ž. Soldin, and G. Giester, Acta Crystallogr. C57 (2001) 409-411.

24. Z. Popović, Ž. Soldin, D. Matković-Čalogović, G. Pavlović, M. Rajić, and G. Giester, Eur. J. Inorg. Chem. (2002) 171-180.

25. Z. Popović, G. Pavlović, Ž. Soldin, J. Popović, D. MatkovićČalogović, and M. Rajić, Struct. Chem. 13 (2002) 415-424.

26. Z. Popović, Ž. Soldin, G. Pavlović, D. Matković-Čalogović, D. Mrvoš-Sermek, and M. Rajić, Struct. Chem. 13 (2002) 425-436.

27. STARe Software V.9.01., MettlerToledo GmbH, 2006.

28. Stoe \& Cie, STADI4 (1995), Diffractometer Control Program for Windows, Darmstadt, Germany.

29. Stoe \& Cie, X-RED (1995), Data Reduction Program for Windows, Darmstadt, Germany.

30. CrysAlisPro, Oxford Diffraction Ltd., (2010), Version 1.171.34.44.

31. L. J. Farrugia, J. Appl. Crystallogr. 32 (1999) 837-838.

32. G. M. Sheldrick, Acta Crystallogr. A64 (2008) 112-122.

33. H. D. Flack Acta Crystallogr. A39 (1983) 876-881.

34. F. H. Allen, O. Kennard, D. G. Watson, L. Brammer, A. G. Orpen, and R. Taylor, J. Chem. Soc. Perkin Trans. 2 (1987) S1-S19.

35. A. L. Spek, Acta Crystallogr., A46 (1990) C34.

36. C. F. Macrae, I. J. Bruno, J. A. Chisholm, P. R. Edgington, P. McCabe, E. Pidcock, L. Rodriguez-Monge, R. Taylor, J. van de Streek, and P. A. Wood, J. Appl. Cryst. 41 (2008) 466-470.

37. M. Cindrić, N. Strukan, T. Kajfež, G. Giester, and B. Kamenar, Z. Anorg. Allg. Chem. 627 (2001) 2604-2608.

38. M. Cindrić, N. Strukan, T. Kajfež, and B. Kamenar, Struct.Chem. 13 (2002) 361-363.

39. H. I. S. Nogueira, Spectrochim. Acta Part A 54 (1998) 1461-1470.

40. M. D. Couce, G. Faraglia, U. Russo, L. Sindellari, and G. Valle, J. Organometall. Chem. 513 (1996) 77-83.

41. E. C. Constable, S. M. Elder, C. A. Palmer, P. R. Raithby, and D. A. Tocher, Inorg. Chim. Acta 252 (1996) 281-291.

42. G. Hoffmann, G. Brockner, and I. Steinfatt, Inorg. Chem. 40 (2001) 977-985

43. L. Stefaniak, Org. Magn. Reson. 12 (1979) 379.

44. B. Korpar-Čolig, Z. Popović, D. Matković-Čalogović, and D. VikićTopić, Organometallics 12 (1993) 4708 -4713.

45. N. Trinajstić, Tetrahedron Lett. 12 (1968) 1529-1532. 
46. F. H. Allen, Acta Crystallogr. Sect. B58 (2002) 380-388.

47. D. Grdenić, Quart. Rev. 19 (1965) 303-328.
48. L. Pauling, The Nature of the Chemical Bond, Third ed., Cornell University Press, Ithaca, New York, 1960. 